\title{
Postoperative complications in patients with oculopharyngeal muscular dystrophy: a retrospective study
}

\section{[Complications postopératoires chez les patients souffrant de dystrophie musculaire} oculo-pharyngée : une étude rétrospective]

Hélène G. Pellerin MD FRCPC, Pierre C. Nicole MD FRCPC, Claude A. Trépanier MD FRCPC, Martin R. Lessard MD FRCPC

Purpose: Oculopharyngeal muscular dystrophy (OPMD) is a genetic disease with autosomal dominant transmission particularly common in Quebec where its prevalence is about I:1000. The main features are bilateral ptosis of the eyelids and dysphagia. These symptoms are frequently treated surgically by levator palpebrae resection (LPR) and cricopharyngeal myotomy (CPM). The objectives of this retrospective chart review were to describe the postoperative complications in OPMD patients undergoing LPR or CPM and to determine their incidence.

Methods: Medical records of all OPMD patients who had either LPR or CPM between 1997 and 2002 were reviewed. The following complications were collected: death, pneumonia, aspiration pneumonitis, airway obstruction, reintubation, and severe coughing and choking caused by profuse secretions.

Results: One hundred and fourteen surgeries on 92 OPMD patients were studied. Fifty-nine were LPR under general anesthesia (LPR-GA) and 22 were LPR under local anesthesia (LPR-LA). Thirty-three surgeries were CPM, all under general anesthesia. There was no death or reintubation. Patients who had LPR-LA had shorter postanesthesia care unit $(P<0.00 \mathrm{I})$ and ambulatory surgery unit $(P<0.00 I)$ stays than those who had LPR-GA. Complications were more frequent after CPM than LPR-GA $(P<0.00$ I $)$.

Conclusion: The complication rate after LPR was low. Both local and general anesthesia are safe alternatives in OPMD patients operated for LPR. Patients having CPM presented more respiratory complications than those having LPR.
Objectif: La dystrophie musculaire oculo-pharyngée (OPMD) est une maladie génétique à transmission autosomale dominante dont la prévalence au Québec est de 1:1000. Ses symptômes cardinaux, la ptose palpébrale et la dysphagie, sont traités par une résection des muscles releveurs des paupières (LPR) et par une myotomie crico-pharyngée (CPM). Les objectifs de cette étude rétrospective étaient de décrire les complications postopératoires des patients atteints de OPMD subissant une LPR ou une CPM et de déterminer leur incidence.

Méthode: Les dossiers médicaux de tous les patients atteints de OPMD et ayant subi une LPR ou une CPM entre 1997 et 2002 ont été révisés. Les complications recherchées ont été: décès, pneumonie, pneumonie d'aspiration, obstruction respiratoire, réintubation et toux sévère avec étouffement causés par des sécrétions abondantes.

Résultats: Cent quatorze chirurgies effectuées chez 92 patients avec OPMD ont été étudiées. Cinquante-neuf étaient des LPR sous anesthésie générale (LPR-GA), 22 des LPR sous anesthésie locale (LPR-LA) et 33 des CPM sous anesthésie générale. II n'y a eu aucun décès ni réintubation. Les patients ayant subi une LPR-LA ont eu un séjour à la salle de réveil et à l'unité de chirurgie ambulatoire d'une durée inférieure à ceux ayant subi une $L P R-G A(P<0,001)$. Les complications ont été plus fréquentes suite aux CPM comparativement aux LPR-GA $(P<0,00 I)$.

Conclusion: La LPR est associée à un faible taux de complications et peut être faite de façon sécuritaire sous anesthésie locale ou générale. La CPM présente plus de complications respiratoires que la LPR.

CAN J ANESTH $2007 / 54: 5 /$ pp 361-365

From the Département d'anesthésie-réanimation, Centre hospitalier affilié universitaire de Québec, Université Laval, Québec, Québec, Canada.

Address correspondence to: Dr. Hélène G. Pellerin, Département d'anesthésie-réanimation, CHA (Hôpital de l'Enfant-Jésus), 1401, 18e rue, Québec, Québec G1J 1Z4, Canada. Phone: 418-649-5807; Fax: 418-649-5918; E-mail: helenpellerin@gmail.com

Funding: This study was supported by departmental funds only.

Presented in part at the 61st Annual Meeting of the Canadian Anesthesiologists' Society, Vancouver, BC, June 17-21, 2005.

Accepted for publication January 16, 2007.

Revision accepted February 1, 2007. 


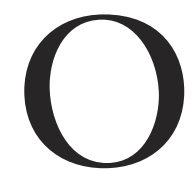
CULOPHARYNGEAL muscular dystrophy (OPMD) was first described by Taylor in 1915 as a neurogenic disease with progressive vagus and glossopharyngeal paralysis associated with ptosis of the eyelids. ${ }^{1}$ In 1948, Amyot reported ten cases in French Canadian families. ${ }^{2}$ However it was only in 1962 that the myopathic origin of the disease was confirmed by Victor et al. who also coined the name for the disease. ${ }^{3}$ In the mid-sixties, André Barbeau conducted a series of clinical and genetic studies, confirming the autosomal dominant transmission of OPMD. ${ }^{4}$ The contribution of these pillar studies is so important that OPMD is often referred to as the "Maladie de Barbeau".

The diagnosis of OPMD is usually made on clinical findings: a family history and the successive appearance of bilateral eyelid ptosis and dysphagia, usually between 50 and $60 \mathrm{yr}$ of age. Oculopharyngeal muscular dystrophy is a progressive disease for which no curative treatment is known. Two types of surgery are often done to alleviate the symptoms of OPMD: levator palpebrae resection (LPR) for correction of bilateral ptosis and cricopharyngeal myotomy (CPM) to improve dysphagia.

Only a few publications about the anesthetic considerations for OPMD patients can be found in the literature and none about perioperative risks. The objectives of this retrospective chart review were to describe the postoperative complications of OPMD patients undergoing LPR or CPM and to determine their incidence.

\section{Methods}

After obtaining the authorization of the medical director of the hospital, the database of the Hôpital de l'Enfant-Jésus was searched to identify patients with OPMD who had undergone either LPR or CPM between 1997 and 2002. Medical records of these patients were also searched to identify other LPR or CPM procedures done prior to 1997 . For every surgical episode identified, demographic data, type of anesthesia, anesthetic medication used, type of surgery, duration of surgery and of postoperative stay were collected. The anesthesia record, the medical and nursing notes, and laboratory reports were reviewed to identify the following complications: pneumonia (fever with positive radiologic findings), aspiration pneumonitis (positive radiologic findings with a witnessed episode of aspiration), airway obstruction, reintubation, and death. During review of the first ten charts, it became evident that many patients had presented multiple episodes of severe coughing and choking caused by the presence of profuse pharyngeal and tracheal

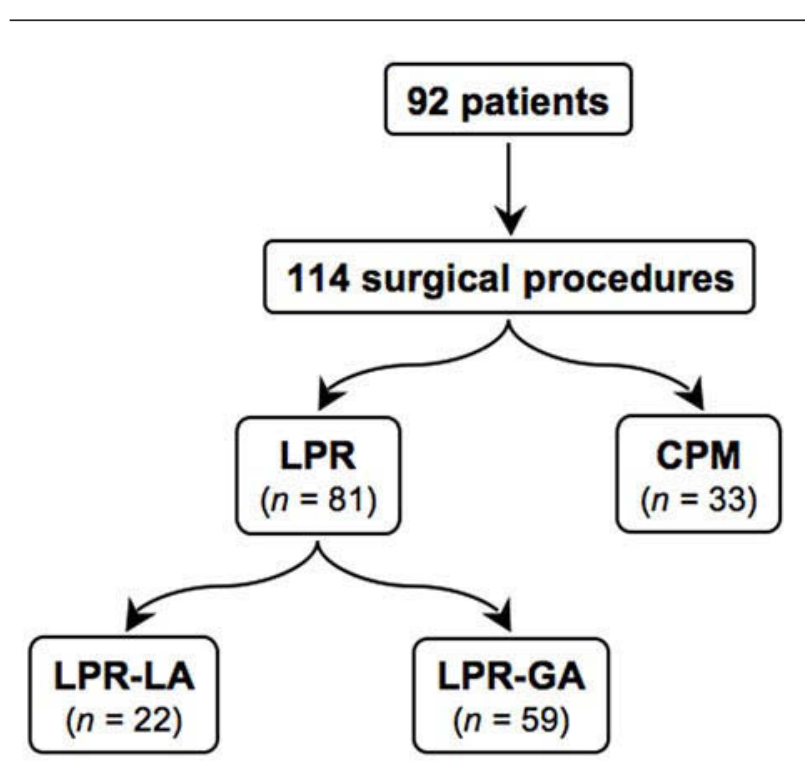

FIGURE Flow diagram of patients included in the retrospective chart review. LPR-LA = levator palpebrae resection done under local anesthesia; LPR-GA = levator palpebrae resection done under general anesthesia; $\mathrm{CPM}=$ cricopharyngeal myotomy done under general anesthesia.

secretions. Thus, it was decided to include this event among the complications sought. The following complications possibly associated with the use of muscle relaxants were sought: prolonged postoperative weakness not alleviated by reversal agents and difference in delay before extubation in patients who did or did not received muscle relaxants intraoperatively.

Comparisons were made between LPR done under local anesthesia (LPR-LA) with those done under general anesthesia (LPR-GA) and between LPR-GA and CPM, which were all done under general anesthesia. Data are presented as mean with SD or proportions. Statistical analysis was done with the Student's $t$ test or the Welch's test for continuous variables and the Fisher's exact test for proportions. Ninety-five percent confidence intervals $\left(\mathrm{CI}_{95 \%}\right)$ were calculated with respect to the incidence of patients presenting complications following LPR or CPM. $P<0.05$ was considered significant.

\section{Results}

Ninety-two patients with OPMD who had undergone a total of 114 LPR or CPM procedures between 1987 and 2002 were identified and had their medical record reviewed (Figure). Six patients had LPR prior to CPM while seven others had CPM prior to LPR. All LPR- 
TABLE I Demographic and perioperative data

\begin{tabular}{|c|c|c|c|}
\hline & $\begin{array}{l}L P R-L A \\
(n=22)\end{array}$ & $\begin{array}{l}L P R-G A \\
(n=59)\end{array}$ & $\begin{array}{l}C P M \\
(n=33)\end{array}$ \\
\hline Age (yr) & $62.6 \pm 7.2$ & $63.1 \pm 6.6^{*}$ & $69.5 \pm 7.8^{*}$ \\
\hline Weight (kg) & $64.5 \pm 14$ & $68.0 \pm 15.3^{*}$ & $53 \pm 14^{*}$ \\
\hline Women (\%) & 59 & $44 \dagger$ & $76 \dagger$ \\
\hline $\begin{array}{l}\text { Preoperative } \\
\text { dysphagia (\%) }\end{array}$ & 68 & $67.8^{*}$ & $100^{*}$ \\
\hline $\begin{array}{l}\text { Duration of } \\
\text { surgery (min) }\end{array}$ & $92.8 \pm 28.1$ & $97.5 \pm 21.5$ & $94.8 \pm 45.6$ \\
\hline $\begin{array}{l}\text { Time before } \\
\text { extubation }(\mathrm{min})\end{array}$ & ----- & $13.3 \pm 10.5 \ddagger$ & $23.1 \pm 24.5 \ddagger$ \\
\hline PACU stay (min) & $26.1 \pm 14 \$$ & $71.8 \pm 26.9 * \mathbb{S}$ & $96.9 \pm 28.9 *$ \\
\hline ASU stay (min) & $237.5 \pm 86.1 \$$ & $346.3 \pm 80.1 \rrbracket \$$ & ---- \\
\hline
\end{tabular}

Data are presented as mean \pm SD or percentage. LPR-LA $=$ levator palpebrae resection done under local anesthesia; LPR-GA = levator palpebrae resection done under general anesthesia; $\mathrm{CPM}=$ cricopharyngeal myotomy done under general anesthesia; PACU $=$ postanesthesia care unit; ASU $=$ ambulatory surgery unit. ${ }^{*} P<$ 0.001 between LPR-GA and CPM, $\uparrow P<0.005$ between LPR-GA and CPM; $\ddagger P<0.01$ between LPR-GA and CPM; $\$ P<0.001$ between LPR-LA and LPR-GA; $₫ n=51$.

TABLE II Postoperative complications

\begin{tabular}{llll}
\hline & $L P R-L A^{*}$ & $L P R-G A^{*}+$ & $C P M+$ \\
\hline Pneumonia & 0 & 0 & $3(9.1)$ \\
Aspiration pneumonitis & 0 & 0 & $1(3)$ \\
Airway obstruction & 0 & $2(3.3)$ & $3(9.1)$ \\
Reintubation & 0 & 0 & 0 \\
Severe coughing and choking & 0 & $3(5)$ & $11(33.3)$ \\
Death & 0 & 0 & 0 \\
\hline
\end{tabular}

Data are presented as number and percentage. LPR-LA $=$ levator palpebrae resection done under local anesthesia; LPR-GA = levator palpebrae resection done under general anesthesia; $\mathrm{CPM}=$ cricopharyngeal myotomy done under general anesthesia. Overall, no complication, five complications and 18 complications were observed after LPR-LA, LPR-GA and CPM respectively.

${ }^{*} P=0.57$ between LPR-LA and LPR-GA; $\dagger P<0.001$ between LPR-GA and CPM.

LA and 51 LPR-GA were done on an outpatient basis while eight LPR-GA and all CPM required hospitalization. One patient had both surgeries on the same day and was considered and analyzed as a CPM.

Demographic and perioperative data are presented in Table I. Compared to patients having LPR-GA, patients undergoing CPM were older $(P<0.001)$, thinner $(P<0.001)$, had a higher percentage of women $(P<0.005)$ and a higher incidence of preoperative dysphagia $(P<0.001)$. Duration of surgery was comparable for LPR-GA and LPR-LA $(P=0.43)$, and for LPR-GA and CPM $(P=0.71)$. However, patients undergoing CPM had a longer delay before extubation at the end of surgery $(P<0.01)$ and had a longer stay in the postanesthesia care unit (PACU)
$(P<0.001)$ than LPR-GA patients. Patients undergoing LPR-GA had a longer stay in the PACU and in the ambulatory surgery unit (ASU) than LPR-LA patients $(P<0.001)$. Eight LPR-GA patients required an overnight hospital stay, while all CPM patients had a hospital stay averaging $3.3 \pm 2.1$ days.

Postoperative complications are presented in Table II. No complication was observed in patients having LPR-LA $\left(\mathrm{CI}_{95 \%}: 0.0 \%-14.9 \%\right)$. In the LPR-GA group, there were five complications occurring after four surgical procedures $\left(6.7 \%, \mathrm{CI}_{95 \%}: 2.0 \%-16.0 \%\right)$. In the CPM group, 18 complications occurred following 12 surgical procedures $\left(36.4 \%, \mathrm{CI}_{95 \%}: 20.0 \%-55.0 \%\right)$. There was no difference in the incidence of postoperative complications between LPR-LA and LPR-GA ( $P$ $=0.57$ ), but CPM was associated with more complications than LPR-GA $(P<0.001)$. The most frequent complication was severe coughing and choking caused by profuse secretions, occurring both in the PACU and on the ward. There was no death or reintubation.

For CPM and LPR-GA, a non-depolarizing muscle relaxant (rocuronium, mivacurium, vecuronium or cisatracurium) or succinylcholine was used to facilitate intubation in $90.3 \%$ and $5.4 \%$ of cases respectively, while no muscle relaxant was used in $4.3 \%$. A rapid sequence induction was used in $12 \%$ of cases. No case of prolonged postoperative weakness or prolongation in the time for extubation in patients who received muscle relaxants was observed. However two patients who had received rocuronium presented airway obstruction in the PACU which was relieved by administration of reversal agents.

\section{Discussion}

This study reports the largest cohort of patients undergoing anesthesia for OPMD specific surgical procedures, and is the first one investigating the incidence of postoperative complications. Its main finding is that CPM carries a higher risk of complications. On the other hand, the risk of complication after LPR is low and comparable whether the surgery is done under local or general anesthesia. This suggests that patients requiring CPM have a more advanced state of disease than those undergoing LPR. This is confirmed by the greater age and lower weight of CPM patients compared to those having LPR. The low number of patients in the LPR-LA limits our ability to draw firm conclusions, but the choice of anesthetic technique does not appear to have a significant impact on the incidence of postoperative complications after LPR. However, local anesthesia allows a shorter recovery time.

Although there are cases of OPMD reported worldwide, the prevalence of OPMD in the province 
of Quebec (Canada) is estimated at 1:1000, among the highest in the world. ${ }^{5}$ In the $17^{\text {th }}$ century, three French sisters with OPMD immigrated to the province of Quebec. All three had a lot of descendants thus spreading the disease in the French Canadian population. The area of L'Islet-Montmagny, on the south shore of the St. Lawrence River East of Quebec City, is where this founder effect is the most evident. Similar clusters of OPMD have also been reported in Israel, and New Mexico. 6,7

Oculopharyngeal muscular dystrophy patients have a normal life expectancy. The degree of dysphagia is the main factor determining prognosis. Dysphagia is caused by progressive weakness of the esophagopharyngeal muscles. These muscles help to propel the food bolus down the esophagus. Frequent choking when swallowing increases the duration of mealtime, eventually leading to malnutrition. Respiratory problems, such as aspiration pneumonitis, also have a negative influence on the quality of life of these patients. Cricopharyngeal myotomy becomes necessary when dysphagia is accompanied by marked weight loss, severe choking, or recurrent pneumonia. ${ }^{8,9}$ The eyelid ptosis has to be corrected when it interferes with vision or when cervical pain appears secondary to constant dorsiflexion of the neck. ${ }^{10}$

The literature on the anesthesia management of OPMD patients is scarce. Landrum et al. and Chun et al. have both described their anesthetic management of one OPMD patient, reporting the safe use of vecuronium and mivacurium respectively, with no postoperative complication. ${ }^{11,12}$ Christopher et al. have reported a case of difficult postoperative extubation in a patient with OPMD. ${ }^{13}$ The patient presented airway obstruction and aspiration pneumonitis, failed two extubation attempts and finally required a tracheostomy. In a prospective pharmacodynamic study in OPMD patients, Caron et al. reported a delayed onset of action with a normal duration of action of cisatracurium. ${ }^{14}$

The retrospective nature of our study carries some limitations, the most obvious being the dependence upon the quality of the data recorded in the medical records. Furthermore, a selection bias cannot be excluded and for these reasons the true incidence of postoperative complications may have been underestimated. It could also be argued that severe coughing and choking should not be considered as a complication. Although it did not result in long term consequences, many patients experienced drop in oxygen saturation during these spells, and it was a major factor in their prolonged PACU and hospital stays. There is also a possibility of a type 2 error when the incidence of complications between LPR-LA and LPR-GA were compared.

This study shows that some anesthetic considerations should be kept in mind for patients with OPMD. Respiratory complications are frequent in the postoperative period of OPMD patients undergoing CPM and these patients should be carefully monitored. Although we did not have access to data on the severity of dysphagia, it is most likely that patients with severe dysphagia and an important weight loss have a higher risk of postoperative complications. However OPMD patients can be treated safely on an outpatient basis after general anesthesia for minor procedures such as LPR. Two patients who had received rocuronium presented airway obstruction in the PACU which was relieved by administration of reversal agents. However, we did not find any case of prolonged postoperative weakness or prolongation in the time for extubation in patients who received muscle relaxants. It remains unclear whether OPMD patients have an increased risk of complications with muscle relaxants since Caron et al. and Plaud et al. have reported normal duration of action for cisatracurium and rocuronium respectively. ${ }^{14,15}$ Obviously, recovery of neuromuscular function must be carefully assessed at the end of surgery. Oculopharyngeal muscular dystrophy patients have difficulty swallowing and retain an increased amount of pharyngeal secretions which should not be mistaken for gastroesophageal reflux. Therefore the anesthesiologist should carefully aspirate pharyngeal secretions before anesthesia induction, but indications for rapid sequence induction should not be different than in the normal surgical population.

In conclusion, in patients with OPMD, general and local anesthesia are safe alternatives for LPR but local anesthesia allows shorter PACU and ASU stays. Cricopharyngeal myotomy is associated with a significant risk of postoperative complications mostly affecting the respiratory system and should be planned and managed accordingly.

\section{References}

1 Taylor EW. Progressive vagus-glossopharyngeal paralysis with ptosis: a contribution to the group of family diseases. J Nerv Ment Dis 1915; 42: 129-39.

2 Amyot $R$. Hereditary, familial and acquired ptosis of late-onset. Can Med Assoc J 1948; 59: 434-8.

3 Victor $M$, Hayes R, Adams RD. Oculopharyngeal muscular dystrophy. A familial disease of late life characterized by dysphagia and progressive ptosis of the eyelids. N Engl J Med 1962; 267: 1267-72.

4 Bouchard JP. André Barbeau and the oculopharyngeal muscular dystrophy in French Canada and North 
America. Neuromuscul Disord 1997; 7(Suppl 1): S5-11.

5 Codere F, Brais B, Rouleau G, Lafontaine E. Oculopharyngeal muscular dystrophy: what's new? Orbit 2001; 20: 259-66.

6 Blumen SC, Nisipeanu P, Sadeh M, et al. Epidemiology and inheritance of oculopharyngeal muscular dystrophy in Israel. Neuromuscul Disord 1997; 7(Suppl 1): S38-40.

7 Becher MW, Morrison L, Davis LE, et al. Oculopharyngeal muscular dystrophy in Hispanic New Mexicans. JAMA 2001; 286: 2437-40.

8 Duranceau AC, Beauchamp G, Jamieson GG, Barbeau $A$. Oropharyngeal dysphagia and oculopharyngeal muscular dystrophy. Surg Clin North Am 1983; 63: 825-32.

9 Fradet G, Pouliot D, Robichaud R, St-Pierre S, Bouchard JP. Upper esophageal sphincter myotomy in oculopharyngeal muscular dystrophy: long-term clinical results. Neuromuscul Disord 1997; 7(Suppl 1): S90-5.

10 Rodrigue D, Molgat $\Upsilon M$. Surgical correction of blepharoptosis in oculopharyngeal muscular dystrophy. Neuromuscul Disord 1997; 7(Suppl 1): S82-4.
11 Landrum AL, Eggers $G W$. Oculopharyngeal dystrophy : an approach to anesthetic management. Anesth Analg 1992; 75: 1043-5.

12 Chun R, Ananthanarayan C. Safe use of mivacurium in oculopharyngeal muscular dystrophy. Can J Anaesth 1998; 45: 1134.

13 Christopher K, Horkan C, Patterson RB, Yodice PC. Oculopharyngeal muscular dystrophy complicating airway management. Chest 2001; 120: 2101-3.

14 Caron MJ, Girard F, Girard DC, et al. Cisatracurium pharmacodynamics in patients with oculopharyngeal muscular dystrophy. Anesth Analg 2005; 100: 393-7.

15 Pland B, Durancean A, Donati F. Dystrophie oculopharyngée (DOP) et blocage neuromusculaire avec le rocuronium. Ann Fr Anesth Réanim 2003; 22: S195 (abstract).

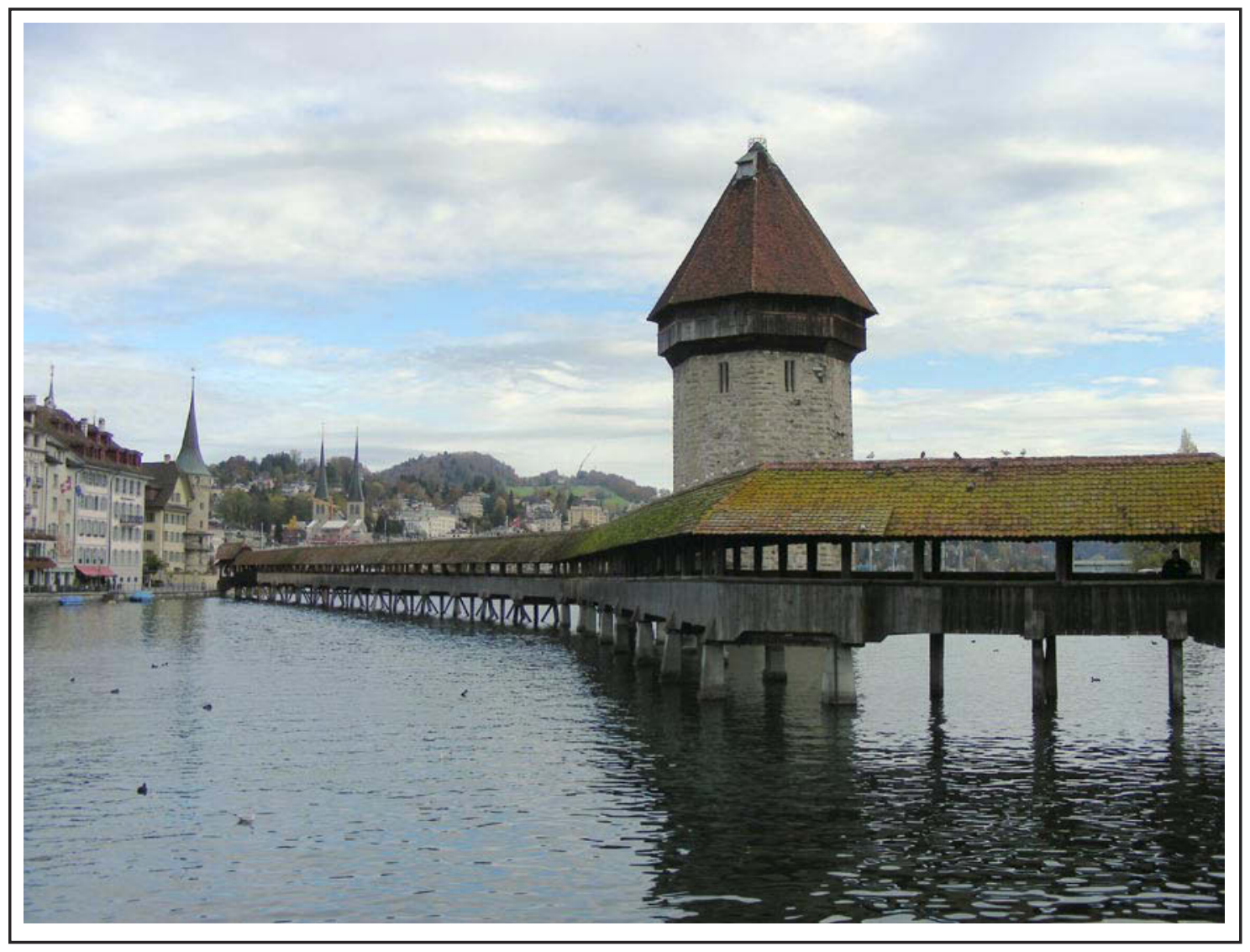

Tower Bridge, Lucerne - Switzerland 